\title{
PTEN Mouse Models of Cancer Initiation and Progression
}

\author{
Yu-Ru Lee and Pier Paolo Pandolfi \\ Cancer Research Institute, Beth Israel Deaconess Cancer Center, Department of Medicine and Pathology, \\ Beth Israel Deaconess Medical Center, Harvard Medical School, Boston, Massachusetts 02215, USA \\ Correspondence: ppandolf@bidmc.harvard.edu
}

\begin{abstract}
Phosphatase and tensin homolog deleted on chromosome 10 (PTEN) is one of the most frequently mutated, deleted, and functionally inactivated tumor suppressor genes in human cancer. PTEN is found mutated both somatically and in the germline of patients with PTEN hamartoma tumor syndrome (PHTS). PTEN encodes a dual lipid and protein phosphatase that dephosphorylates the lipid phosphatidylinositol-3,4,5-trisphosphate $\left(\mathrm{PIP}_{3}\right)$, in turn negatively regulating the oncogenic PI3K-AKT pathway, a key proto-oncogenic player in cancer development and progression. Because of importance of PTEN in tumorigenesis, a large number of sophisticated genetically engineered mouse models (GEMMs) has been designed to elucidate the underlying mechanisms by which the "PTEN pathway" promotes tumorigenesis, while simultaneously providing a well-tailored system for the identification of novel therapies and offering platforms for new drug discoveries. This review summarizes the major cancer mouse models through which the PTEN pathway has been genetically deconstructed, and outlines the rapid development of GEMMs toward more detailed functional and tissue-specific analysis.
\end{abstract}

$P^{\text {hos }}$ hosphatase and tensin homolog deleted on chromosome 10 (PTEN) is frequently somatically mutated or deleted in human cancers. In 1997, genetic studies first identified PTEN as a putative tumor suppressor (Li et al. 1997; Teng et al. 1997), and the importance of PTEN in tumor suppression was soon reaffirmed by the identification of germline PTEN mutations in PTEN hamartoma tumor syndrome (PHTS), including mutation positive subsets of Cowden syndrome (OMIM ID: 158350), Bannayan-Riley-Ruvalcaba syndrome (OMIM ID: 158350), Proteus syndrome (OMIM ID: 176920), and Proteus-like syndrome (Arch et al. 1997; Liaw et al. 1997; Zhou et al. 2001). Genetic inactivation of Pten in mice demonstrated its tumorsuppressive role in multiple tumors of various origins, and suggested the haploinsufficiency of PTEN in terms of tumor suppression in some tissue types (Di Cristofano et al. 1998, 1999; Suzuki et al. 1998; Podsypanina et al. 1999). Moreover, partial loss of PTEN function was found to be sufficient to trigger some cancer types, while a reduction of PTEN levels below $50 \%$ increased tumor progression in some human tissues and genetically engineered mouse models (GEMMs). These observations suggest that a continuum rather than a stepwise model

Editors: Charis Eng, Joanne Ngeow, and Vuk Stambolic

Additional Perspectives on The PTEN Family available at www.perspectivesinmedicine.org

Copyright (C) 2020 Cold Spring Harbor Laboratory Press; all rights reserved; doi: 10.1101/cshperspect.a037283

Cite this article as Cold Spring Harb Perspect Med 2020;10:a037283 
of PTEN activity best describes the process triggering tumor initiation and progression (Alimonti et al. 2010a; Berger et al. 2011).

PTEN is a dual-specificity protein and lipid phosphatase, and its primary substrate is the second messenger phosphatidylinositol 3,4,5triphosphate $\left(\mathrm{PIP}_{3}\right)$, which is hydrolyzed to phosphatidylinositol 4,5-biphosphate $\left(\mathrm{PIP}_{2}\right)$ by PTEN lipid phosphatase activity (Song et al. 2012; Lee et al. 2018). PTEN suppresses the phosphatidylinositol 3-kinase (PI3K) pathway by inhibiting membrane recruitment and activation of the oncogenic AKT in a $\mathrm{PIP}_{3}$-dependent manner, thereby inhibiting cell proliferation, growth, and survival. Accordingly, PTEN has emerged as a crucial node in a wide range of cancer therapies (Song et al. 2012; Lee et al. 2018).

PTEN is strictly regulated, and its deregulation through aberrant subcellular localization or posttranslational modifications (or both) occurs frequently in tumorigenesis (Lee et al. 2018). Mechanistically, monoubiquitination or sumoylation regulates the import of PTEN into the nucleus where it functions as a scaffold and exerts $\mathrm{PIP}_{3}$-independent functions in genomic integrity, induction of apoptosis, cell-cycle control, and senescence (Trotman et al. 2007; Salmena et al. 2008; Song et al. 2012; Bassi et al. 2013; Lee et al. 2018). In the cytoplasm, scaffolding by PTEN regulates not only the activity of inositol 1,4,5-triphosphate receptors ( $\left.\mathrm{IP}_{3} \mathrm{Rs}\right)$, and consequently, $\mathrm{Ca}^{2+}$-mediated apoptosis, but also the activation of the oncogenic tumor necrosis factor (TNF)-nuclear factor $\mathrm{KB}$ (NF$\kappa B)$ pathway (Kuchay et al. 2017; Zhao et al. 2017). Intriguingly, a recent study found that PTEN also exists as a dimer, and that dimer formation and recruitment at the plasma membrane are crucial for PTEN activation and function (Papa et al. 2014). Moreover, through combined biochemical and genetic approaches, it was also demonstrated that the HECT-type WWP1 specifically triggers atypical nondegradative polyubiquitination of PTEN to suppress its dimerization, membrane recruitment, and tumor-suppressive functions both in vitro and in vivo (Lee et al. 2019). Importantly, both genetic ablation and pharmacological inhibition of
WWP1 were found to trigger PTEN reactivation to unleash its tumor-suppressive activity. These recent discoveries offer hope that the elucidation of the mechanisms controlling PTEN protein levels and activity will open new therapeutic avenues for cancer prevention and treatment through restoration of the protein's tumorsuppressive activity.

\section{OVERVIEW OF GENETICALLY ENGINEERED Pten MOUSE MODELS}

Genetically engineered Pten mouse models have multiplied in number over the past 20 years, but can generally be classified into three distinct groups according to the level of PTEN manipulation and the specifics of their outcomes or goals. These models include (1) down-regulation of PTEN, either alone or in combination with loss-of-function of another tumor suppressor or gain-of-function of an oncogene to accelerate cancer progression; (2) elevation of PTEN expression and function; and (3) mouse models of cancer-associated PTEN mutations. The most relevant Pten mouse models are schematically shown in Figure 1 and described below.

\section{Down-Regulation of PTEN, Either Alone or in Combination with Loss-of-Function of Another Tumor Suppressor or Gain-of-Function of an Oncogene to Accelerate Cancer Progression}

This group of models can be divided into several subgroups.

\section{Whole-Body Manipulation of Pten}

The earliest GEMMs were developed soon after the identification of PTEN as a candidate tumor suppressor gene (Di Cristofano et al. 1998; Suzuki et al. 1998; Podsypanina et al. 1999). The first Pten homozygous knockout mice proved embryonically lethal at days 3.5-9.5 (Di Cristofano et al. 1998), but heterozygous Pten $^{+/-}$mice survived to maturity, and developed a broad range of neoplastic lesions, including prostate intraepithelial neoplasia (PIN), lymphomas, dysplastic intestinal polyps, and endometrial complex atypical 
1. Whole-body knockout of Pten

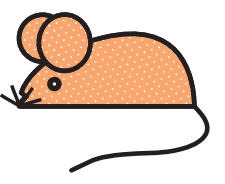

Pten $^{+/}$

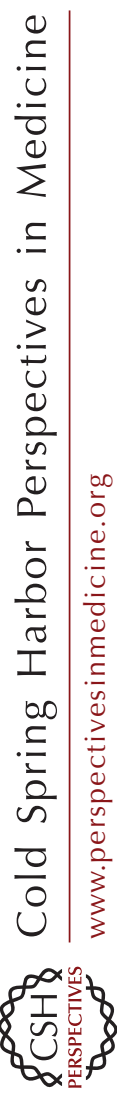

3. Tissue-specific deletions of Pten

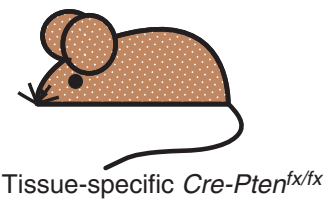

5. Elevation of PTEN expression or function

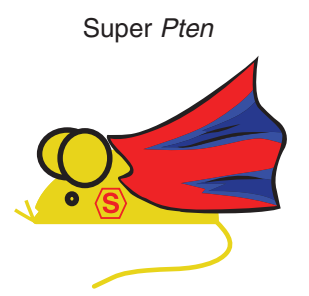

2. Hypomorphic Pten models

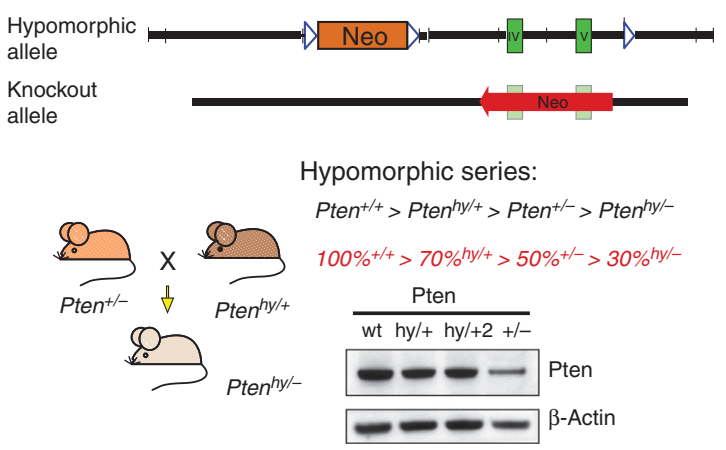

4. Compound Pten mouse models

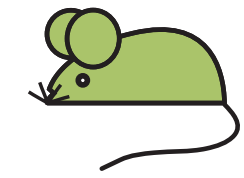

$P b^{\text {cre }} ;$ Pten $^{f x / f x} ; p 53^{f x / f x}$ $P b^{c r e} ;$ Pten $^{f x / f x} ; P 53^{f x / f x} ; . . . .$.

6. Knockin of cancer-associated Pten mutations

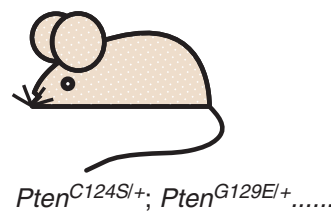

Figure 1. Genetically engineered Pten mouse models. Genetically engineered Pten mouse models can be classified into six distinct groups. These include (1) whole-body knockout of Pten; (2) generation of hypomorphic Pten model by targeting intron 3 of Pten with a cytomegalovirus (CMV) promoter-driven neomycin (neo) cassette, which reduced PTEN expression to $80 \%$. These Pten ${ }^{h y /+}$ mice were then crossed with $\mathrm{Pten}^{+/-}$mice to generate hypomorphic mouse cohorts with decreasing levels of PTEN expression $\left(\right.$ Pten $^{+/+}>$Pten $^{\text {hy/+ }}>$ Pten $^{+/-}>$Pten $\left.^{\text {hy/-}}\right)$; (3) tissue-specific deletion of Pten; (4) compound mouse models: combined Pten deletion along with another tumor suppressor or oncogene; (5) elevation of PTEN expression or function through bacterial artificial chromosome (BAC) technology of additional copies of the Pten locus; and (6) modeling cancer-associated Pten mutations in mice through knockin and CRISPR technology.

hyperplasia (Di Cristofano et al. 1998; Suzuki et al. 1998; Podsypanina et al. 1999). Some of these lesions, such as intestinal polyps and endometrial hyperplasia, are also observed in human Cowden syndrome (Arch et al. 1997; Liaw et al. 1997; Zhou et al. 2001).

\section{Hypomorphic Pten Mouse Model}

It has been hypothesized that subtle variations in the tumor suppressor gene adenomatous polyposis coli (APC) levels can promote colon cancer development (Yan et al. 2002). To explore this hypothesis in the context of PTEN 
biology, the Pandolfi Laboratory generated a Pten hypomorphic mouse model (Pten ${ }^{\text {hy/t}}$ ) by targeting intron 3 of Pten with a neomycin (neo) cassette, under the control of a cytomegalovirus (CMV) promoter, which in turn led to transcriptional interference and subsequently reduced PTEN expression to $80 \%$ of its normal baseline level. These Pten ${ }^{h y /+}$ mice were then crossed with $\mathrm{Pten}^{+/-}$mice to generate hypomorphic mouse cohorts with decreasing levels of PTEN expression $\left(\right.$ Pten $^{+/+}>$Pten $^{\text {hy/+}}>$ Pten $^{+/-}>$ Pten $\left.{ }^{h y /-}\right)$. Pten ${ }^{h y / t}$ mice developed a spectrum of neoplastic lesions (mammary tumors, uterine tumors, lymphadenopathy, intestinal polyps, and pheochromocytoma), with breast tumors present with the highest penetrance. All breast tumors analyzed in these cohorts retained two intact copies of Pten and maintained PTEN levels above heterozygosity (Alimonti et al. 2010a). Reduction in PTEN levels below 50\% further accelerated prostate cancer progression (Trotman et al. 2003), suggesting that the process of tumor development is governed by a continuum model of PTEN tumor suppression rather than stepwise alteration of PTEN levels (Fig. 2; Berger et al. 2011).

\section{Tissue-Specific Deletion of Pten}

LoxP/CRE technology has enabled the generation of tissue-specific PTEN deletion models, which have resulted in tumor development specifically in those tissues subject to loss of PTEN expression (Table 1), while also yielding a number of unexpected biological outcomes (Kishimoto et al. 2003; Andres-Pons et al. 2007; Renner et al. 2008; Renner and Carnero 2009; Inoue et al. 2013):

Complete Loss of Pten in the Prostate Triggers Cellular Senescence, a Potent FailSafe Mechanism to Suppress Tumor Growth in Prostate Cancers

Mouse model studies have revealed the crucial roles of PTEN in prostate cancer (Civenni et al. 2018). Although partial loss of Pten increases cellular growth and proliferation (Trotman et al. 2003; Alimonti et al. 2010a; Berger et al.

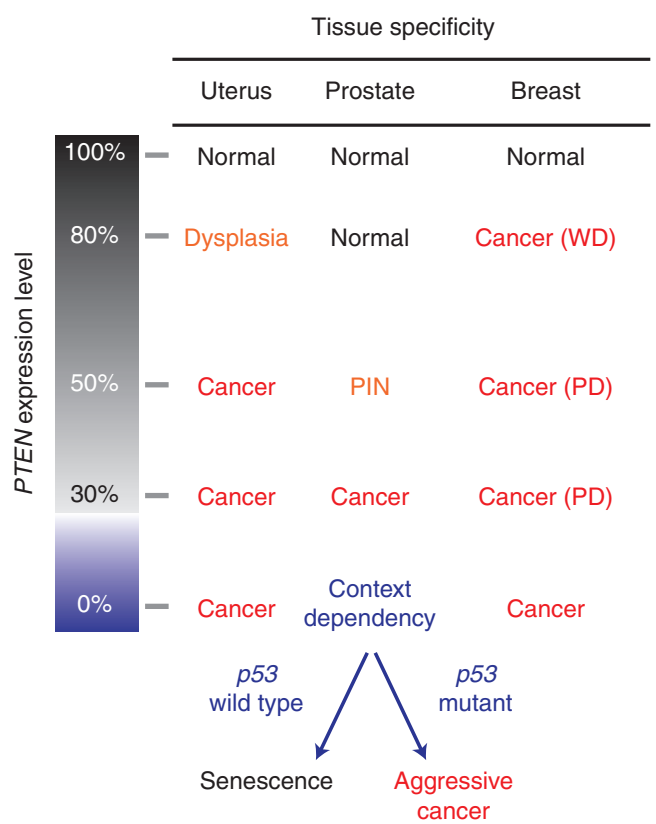

Figure 2. Tissue specificity and context dependency of phosphatase and tensin homolog deleted on chromosome 10 (PTEN) tumor suppression. The phenotypic outcome of reduction in PTEN expression is differentially manifested depending on tissue type and genetic background. The effect of complete loss of PTEN is highly context-dependent because of the obligate haploinsufficiency caused by PTEN-loss-induced cellular senescence (PICS). (From Berger et al. 2011; adapted, with permission, from Springer Nature (c) 2011.)

2011), complete loss of Pten in the prostate epithelium results in cellular senescence (Chen et al. 2005; Alimonti et al. 2010b), which functions as a fail-safe mechanism that restricts tumor progression. These data explain why complete loss of Pten alone in the mouse prostate results in indolent tumors with minimally invasive features after a long latency, and why complete loss of Pten is not frequently observed during cancer initiation. Pten loss can be prevalent, however, in metastatic and advanced prostate cancer, where the pathways responsible for senescence are frequently dysregulated. Mechanistic studies have revealed that PTENloss-induced cellular senescence (PICS) can be attributed to the up-regulation of both p53 and p16 (Chen et al. 2005; Alimonti et al. 2010b; Song et al. 2011). 
Table 1. Tissue-specific Pten deletion and biological outcomes

\begin{tabular}{lc}
\hline $\begin{array}{l}\text { Tissue-specific } \\
\text { deletion of Pten }\end{array}$ & Phenotype \\
\hline $\begin{array}{l}\text { Mammary-specific } \\
\text { knockout }\end{array}$ & Proliferation and dysplasia \\
Hepatocyte-specific & Hepatocellular carcinoma and \\
knockout & steatohepatitis \\
T-cell-specific & Defects in central and \\
knockout & peripheral tolerance \\
Prostate-specific & Senescence \\
knockout & \\
\hline
\end{tabular}

Mammary-Specific Deletion of Pten Increases Proliferation and Dysplasia

Conditional knockout of Pten in the mammary gland was found to lead to increased intraluminal focal hyperplasia and early development of mammary tumors, a consequence of the loss of Pten function in controlling the proliferation, differentiation, and apoptosis of mammary epithelial cells ( $\mathrm{Li}$ et al. 2002).

\section{Hepatocyte-Specific Pten Deficiency Leads to Hepatocellular Carcinomas and Steatohepatitis}

PTEN expression is reduced or absent in 50\% of hepatoma patients, and hepatocyte-specific deletion of Pten (Albumin Cre; Pten ${ }^{f x / f x}$ ) in mice leads to steatohepatitis with triglyceride accumulation and hepatomegaly (Horie et al. 2004). Furthermore, loss of Pten in the liver also triggered liver cell adenomas in $47 \%$ of mice by 44 weeks of age, while $100 \%$ of mice livers examined exhibited insulin hypersensitivity. Mechanistically, Pten knockout hepatocytes were not only hyperproliferative, with higher phosphorylation of AKT and ERK but also displayed elevated levels of PPAR $\gamma$ and SREBP1c. Recently, new transformative approaches have been implemented to rapidly generate cancer models in mice by using CRISPR technology (Xue et al. 2014; Wang et al. 2015). Both hydrodynamic injection and adenoassociated virus (AAV)-mediated delivery methods of plasmid DNA expressing Cas9 and Pten targeting
sgRNA to the liver increased AKT activation, resulting in steatohepatitis and hepatomegaly phenotypes in mouse livers, phenocopying the effects of Pten deletion in mice by using LoxP/ Cre technology. These data provide evidence of the crucial roles played by PTEN in regulating hepatocyte homeostasis, glucose metabolism, lipogenesis, and tumorigenesis (Horie et al. 2004).

T-cell-Specific Deletion of Pten Results in Defects in Central and Peripheral Tolerance

Pten-deficient T cells were hyperproliferative, resistant to apoptosis, and exhibited increased phosphorylation of AKT and ERK, which led to elevated levels of B cells and $\mathrm{CD}^{+}{ }^{+} \mathrm{T}$ cells in the periphery, as well as spontaneous activation of $\mathrm{CD} 4^{+} \mathrm{T}$ cells, autoantibody production, and hypergammaglobulinemia. Moreover, these mice showed increased thymic cellularity, in part as a result of a defect in thymic negative selection. A study of this model found that all mice developed $\mathrm{CD} 4^{+} \mathrm{T}$-cell lymphomas by 17 weeks of age (Suzuki et al. 2001). Similar immune-related disorders were also found in Pten heterozygous $\left(\right.$ Pten $\left.^{+/-}\right)$mice. These mice developed a lethal polyclonal autoimmune disorder with features reminiscent of those observed in Fas-deficient mutants. Mechanistically, Fas-mediated apoptosis was impaired in Pten $^{+/-}$mice, and T lymphocytes from these mice showed reduced activation-induced cell death and increased proliferation upon activation (Di Cristofano et al. 1999). These results demonstrate the crucial roles of PTEN in maintaining immune response homeostasis.

\section{Combination of Pten Loss with Either Loss-of- Function of a Tumor Suppressor or Gain-of- Function of an Oncogene}

Given the impact of PTEN loss in tumorigenesis, a strategy was soon designed to unravel the specific pathway(s) and the underlying mechanisms involved in PTEN loss triggered advanced cancer progression (Table 2). To this end, Pten ${ }^{+/}$mice were bred with Cdkn1b (encoding $\left.\mathrm{p} 27^{\mathrm{kip} 1}\right)^{-/}-$mice. Indeed, the concomi- 
Y.-R. Lee and P.P. Pandolfi

Table 2. Selected genetically engineered Pten mouse models in cancer initiation and progression

\begin{tabular}{|c|c|}
\hline Genotype & Phenotype \\
\hline $\mathrm{Pten}^{+/-} ; \mathrm{Cdkn} \mathrm{b}^{+/-}$or $\mathrm{Pten}^{+/-} ; \mathrm{Cdkn} \mathrm{b}^{-/-}$ & $\begin{array}{l}\text { Accelerates spontaneous neoplastic transformation and } \\
\text { incidence of prostate intraepithelial neoplasia (PIN) } \\
\text { development }\end{array}$ \\
\hline Pten $^{+/-} ; \mathrm{Nk} \times 3.1^{+/-}$or Pten ${ }^{+/-} ; \mathrm{Nk} \times 3.1^{-/-}$ & $\begin{array}{l}\text { Increases the progression from PIN to high-grade PIN or early } \\
\text { carcinoma }\end{array}$ \\
\hline $\mathrm{Pten}^{+/-} ; \mathrm{Tsc}^{+/-}$or $\mathrm{Pten}^{+/-} ; \mathrm{Tsc}^{-/-}$ & Increases the progression from PIN to prostate cancer \\
\hline 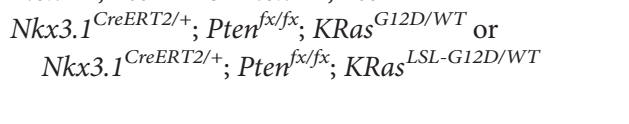 & $\begin{array}{l}\text { Accelerates cancer progression, accompanied by epithelial-to- } \\
\text { mesenchymal transition (EMT) and macrometastasis to lung } \\
\text { and liver }\end{array}$ \\
\hline Hb13-Myc; Hb13 $3^{\text {cre }}$ Pten ${ }^{f x / f x}$ & Develops lethal adenocarcinoma with distant metastases \\
\hline $\mathrm{Pb}^{\text {cre }} ;$ Pten $^{f x / f x} ; F g f 8 b$ & $\begin{array}{l}\text { Develops prostatic adenocarcinoma with readily detectable } \\
\text { lymph node metastasis }\end{array}$ \\
\hline $\mathrm{Pb}^{\text {cre }} ;$ ERG; Pten $^{+/-}$or Pten $^{f x / f x} ; \mathrm{R} 26^{\mathrm{ERG}}$ & Increases high-grade PIN to prostatic invasive adenocarcinoma \\
\hline $\mathrm{Pb}^{\text {cre }} ;$ Pten $^{f x / f x} ;$ Sox 9 & $\begin{array}{l}\text { Promotes proliferation and cooperates with Pten loss to trigger } \\
\text { tumor formation }\end{array}$ \\
\hline $\mathrm{Pb}^{\text {cre }} ;$ Pten $^{f x / f x} ;$ Her 2 & Develops aggressive prostate cancers \\
\hline $\mathrm{Pb}^{\text {cre }} ;$ Pten $^{f x / f x} ;$ Notch & Promotes EMT and FOXC2-dependent metastases \\
\hline $\mathrm{Pb}^{\mathrm{cre}} ;$ Pten $^{f x / f x} ; B m i 1$ & Develops invasive adenocarcinoma \\
\hline $\mathrm{Pb}^{\text {cre }} ;$ Pten $^{f x / f x} ; p 53^{f x / f x}$ & $\begin{array}{l}\text { Overcomes Pten-loss-induced senescence and develops invasive } \\
\text { adenocarcinoma }\end{array}$ \\
\hline $\mathrm{Pb}^{\text {cre }} ; \operatorname{Pten}^{f x / f x} ; \operatorname{Smad} 4^{f x / f x}$ & $\begin{array}{l}\text { Develops aggressive prostate cancer with metastasis to lymph } \\
\text { nodes and lungs }\end{array}$ \\
\hline $\begin{array}{l}\mathrm{Pb}^{\text {cre }} ; \text { Pten }^{f x / f x} ; p 53^{f x / f x} ; \text { Smad } 4^{f x / f x} \text { or } \mathrm{Pb}^{\text {cre }} ; \text { Pten }^{f x / f x} ; \\
\quad \text { Smad4 } 4^{f x / f x} ; \text { TTert }\end{array}$ & Increases prostate cancer progression with bone metastasis \\
\hline $\mathrm{Pb}^{\text {cre }} ;$ Pten $^{f x / f x} ;$ Gata $^{f x / f x}$ & Increases tumor progression and invasion \\
\hline $\mathrm{Pb}^{\mathrm{cre}} ; P_{t e n}{ }^{f x / f x} ; Z b t b 7 a^{f x / f x}$ & $\begin{array}{l}\text { Accelerates prostate cancer progression with bypass of Pten-loss- } \\
\text { induced senescence }\end{array}$ \\
\hline $\mathrm{Pb}^{\text {cre }} ;$ Pten $^{f x / f x} ; P m t^{f x / f x}$ & Develops lethal and metastatic prostate cancer \\
\hline
\end{tabular}

tant inactivation of one allele of Pten and one or both $c d k n 1 b$ alleles accelerated spontaneous neoplastic transformation and PIN development around 13-22 weeks with 100\% penetrance (Di Cristofano et al. 2001). Similarly, crossing $N k \times 3.1^{-/-}$, lacking a transcriptional factor that plays an important role in prostate development and tumorigenesis, and $\mathrm{Pten}^{+/-}$ mice increased progression from PIN to highgrade PIN with $60 \%$ penetrance in 26 weeks or early carcinoma with $100 \%$ penetrance in 52 weeks (Kim et al. 2002). These mice even exhibited invasive carcinoma once they had reached 1 year of age (Abate-Shen et al. 2003). Interestingly, genetic analysis of Pten and Tsc2 functional interactions revealed asymmetrical haploinsufficiency in tumor suppression. Both Pten and Tsc2 were haploinsufficient for suppression of tumorigenesis initiated by Pten het- erozygosity (e.g., PIN), while neither Pten nor Tsc2 were found to be haploinsufficient for repression of carcinogenesis arising from $T s c 2$ heterozygosity (e.g., renal cancer), providing a rationale for the asymmetrical haploinsufficiency of Pten or Tsc2 in tumor suppression (Ma et al. 2005). The insights gleaned from these studies have spurred scientists to continue to take advantage of tissue-specific conditional knockout of Pten to further explore the crucial and contextdependent roles of PTEN in tumorigenesis.

Conditional Pten knockout mice have also been crossed with mice expressing either gainof-function oncogenes or loss-of-function tumor-suppressive genes. For example, when $N k x 3.1^{\text {Cre;ER(T2)+ }}$; Pten ${ }^{\text {flox/flox }}$ mice were crossed with lox-stop-lox BrafV600E mice, the resulting hybrids developed lethal prostate tumors that were resistant to castration and metastasized 
to the lymph nodes and lungs in $\sim 30 \%$ of cases (Wang et al. 2012). Moreover, crossing $N k \times 3.1^{\mathrm{Cre} ; E R(T 2)+} ;$ Pten $^{\text {flox/flox }}$ mice with mice expressing constitutively active KRAS $\left(K_{-r a s}{ }^{G 12 D / W T}\right)$ resulted in accelerated Pten loss-driven progression, coupled with epithelial-to-mesenchymal transition (EMT) and macrometastases in the lungs and liver with 100\% penetrance, but not bone metastases (Mulholland et al. 2012). Similar results have been observed in Nkx3.1 ${ }^{\mathrm{Cre} ; \mathrm{ER}(\mathrm{T} 2)+}$; Pten ${ }^{\text {flox/flox }}$ mice crossed with a cre-dependent oncogenic KRAS cassette $\left(\mathrm{Kras}^{\mathrm{LSL}-\mathrm{G1} 2 \mathrm{D} /+}\right)$. These mice developed aggressive adenocarcinoma and macrometastasis with $100 \%$ penetrance in both lung and liver, with oncogenic Ets variant 4 (Etv4) up-regulation (Aytes et al. 2013). Likewise, an increase in the penetrance of aggressive prostate cancer was observed when Pten loss was combined with another oncogenic stimulus such as MYC (Hubbard et al. 2016), ERG (Carver et al. 2009; Chen et al. 2013), SOX9 (Thomsen et al. 2010), FGF8b (Zhong et al. 2006), HER2 (Ahmad et al. 2011), NOTCH (Kwon et al. 2016), and BMI1 (Nacerddine et al. 2012).

Although PTEN is a crucial suppressor of prostate tumorigenesis, progression from PIN to aggressive adenocarcinoma and castrationresistant prostate cancer (CRPC) was found to require additional genetic perturbations. The tumor suppressor p53 was found to be a strong candidate for these manipulations. Like PTEN, TP53 is among the most commonly somatically inactivated or mutated genes in human cancer, including advanced prostate cancer (Di Cristofano and Pandolfi 2000; Vogelstein et al. 2000; Robinson et al. 2015; Abida et al. 2019). To explore the results of the mutual inactivation of both tumor suppressors, $\mathrm{Pb}^{\mathrm{Cre} 4} ;$ Pten flox/flox mice were bred with $p 53^{\text {flox/flox }}$ mice to generate $\mathrm{Pb}^{\mathrm{Cre} 4} ;$ Pten ${ }^{\text {flox/flox }} ; p 53^{\text {flox/flox }}$ mice. Surprisingly, conditional inactivation of Trp53 in the mouse prostate failed to produce a tumor phenotype, while complete Pten inactivation in the prostate induced indolent invasive prostate cancer after long latency. However, combined inactivation of Pten and Trp53 in mice led to the development of invasive adenocarcinoma as early as 2 weeks of age, and proved lethal to mice by 7 months of age. Mechanistically, complete genetic inactivation of Pten was shown to trigger a p53-dependent senescence program that restricted tumorigenesis, and was bypassed by compound loss of Trp53. These results suggest a model for cooperative tumor suppression in which p53 functions as a potent fail-safe mechanism for Pten-deficient tumors (Chen et al. 2005).

Apart from p53 induction, the transforming growth factor $\beta$ (TGF- $\beta$ )/Smad4 tumor-suppressive pathway is also activated in advanced prostate cancer upon loss of PTEN expression. Hence, combined prostate-specific Pten and Smad4 knockout led to the development of aggressive prostate cancer with metastasis to the lymph nodes and lungs (Ding et al. 2011). Further combinations with either overexpression of active telomerase in double Pten/Trp53 knockout mice or triple knockout of Pten/ Trp53/Smad4 led to bone metastasis (Ding et al. 2012). Among other PTEN-deficient models, prostate-specific knockout of Gata3 combined with Pten loss was shown to increase tumor progression and invasion (Nguyen et al. 2013). Moreover, compound prostate-specific inactivation of zinc finger and BTB-domain-containing protein $7 \mathrm{~A}(Z b t b 7 a)$, which was genetically lost and down-regulated in a subset of advanced prostate cancers, resulted in a marked acceleration of Pten-loss-driven prostate cancer progression through the activation of Sry (sexdetermining region Y)-box9 (Sox9) oncogenic activity, and further bypass of Pten-loss-induced cellular senescence (Wang et al. 2013). Recently $P M L$ was found to be frequently codeleted with PTEN in metastatic prostate cancer, and that combined conditional inactivation of $P m l$ in the mouse prostate triggers the transformation of indolent Pten-null tumors into lethal and metastatic prostate cancer. Transcriptional profiling analyses of tumors revealed MAPK reactivation and hyperactivation of the prometastatic SREBP transcriptional program (Chen et al. 2018). On this basis, a high-fat diet (HFD) administered to mice was capable of inducing lipid accumulation in prostate tumors, and was shown to be sufficient to trigger metastasis in a nonmetastatic Pten-null mouse model (Chen et al. 2018). So far, the discoveries summarized above demon- 
strate the power of GEMMs to deconvolute and reconstruct the genetic makeup and complexity of tissue-specific human cancers, and lay a framework for future drug discovery and therapeutic strategies.

\section{Elevation of PTEN Expression and Function}

Partial loss of PTEN is known to trigger cancer susceptibility and tumor progression (Di Cristofano et al. 1998; Suzuki et al. 1998; Podsypanina et al. 1999; Song et al. 2012; Lee et al. 2018). Therefore, both elevation of PTEN expression and restoration of PTEN activity hold promise as potential strategies for cancer prevention and therapy. Several transgenic mouse colonies were generated with PTEN expression elevated to varying levels through a bacterial artificial chromosome (BAC)-mediated approach. The resulting "Super PTEN" mice have proved to be viable, despite decreased body size (GarciaCao et al. 2012). Importantly, elevated PTEN levels led to increased energy expenditure and reduced glucose and glutamine uptake. On this basis, Super PTEN mice were lean and displayed healthy metabolism. Importantly, mice and cells derived from these mice were resistant to oncogenic transformation, while PTEN elevation also prevented the development of key tumorigenic features, including glutaminolysis and the Warburg effect. These data suggest the possibility of strategic tumor prevention and therapy through pharmacological increase in wild-type PTEN level or function.

In an ongoing effort to explore the potential impact of the restoration and elevation of PTEN function, the Pandolfi Laboratory has also carried out screenings for PTEN negative regulators. Such screenings have identified an HECT domain ubiquitin E3 ligase, WWP1, which specifically triggers PTEN K27-linked polyubiquitination to suppress its dimerization, membrane recruitment, and tumor-suppressive function. Furthermore, WWP1 was found to be transcriptionally activated by the MYC proto-oncogene, while genetic depletion of $W w p 1$ in $M y c$-driven mouse models ( $\mathrm{Hi}-\mathrm{Myc} ; \mathrm{Wwp1^{-/- }}$ ) of prostate cancer was found to increase PTEN membrane recruitment and tumor-suppressive function, leading to inhibition of the PI3K-AKT pathway and MYC-driven tumorigenesis (Lee et al. 2019). These findings demonstrate that WWP1 acts downstream of MYC, and that inactivation of WWP1 can restore and enhance the tumorsuppressive activity of PTEN, paving the way toward a long-sought approach for tumor suppressor reactivation for cancer prevention and treatment.

\section{Mouse Models of Cancer-Associated PTEN Mutations}

Beyond frequent PTEN somatic mutations in multiple human cancers, germline PTEN mutations define a range of tumor syndromes referred to as PHTS, including the PTEN mutation positive subset of Cowden syndrome and BannayanRiley-Ruvalcaba syndrome (Arch et al. 1997; Liaw et al. 1997; Zhou et al. 2001; Yehia et al. 2019). Indeed, GEMMs with Pten mutations have emerged as an effective means of studying the underlying mechanisms and physiological functions by which PTEN mutations impact these syndromes. Charis Eng's group at Cleveland Clinic was the first group to generate germline Pten mutations in mice (R233Q; R234Q; K266N; K267Q), which they termed Pten ${ }^{m 3 m 4}$ mice for brevity. They generated Pten ${ }^{m 3 m}$ mice by introducing all these missense mutations into exon 7 of the mouse Pten locus. These mutations collectively target the sequences analogous to the third and fourth nuclear localization-like sequences found in the human PTEN gene (Chung et al. 2005). Homozygous Pten ${ }^{\text {m3m4 }}$ mice displayed reduced PTEN protein levels and cytoplasmically predominant PTEN, resulting in region-specific increases in brain weight and AKT activation. Importantly, the mice developed macrocephaly, a major component of PHTS, and recapitulated features of high-functioning autism spectrum disorder (ASD) with sex-specific increases in social motivation in male mice, poor balance, and normal recognition memory (Mester et al. 2011; Tilot et al. 2014).

Caserta et al. (2015) generated and characterized a Pten knockin mouse model harboring a phenylalanine to valine mutation (Pten F341 V or Pten $^{F V}$ for brevity) in the C2 domain of 
PTEN, with the former observed in human cancer. Although homozygous Pten ${ }^{F V / F V}$ embryos exhibited reduced levels of PTEN, the cells still had intact AKT signaling, developed normally, and were carried to term. Interestingly, $\mathrm{Pten}^{\mathrm{FV/+}}$ mice developed tumors in the mammary gland, stomach, thymus, and adrenal medulla, but not in the organs that are usually sensitive to Pten depletion, including the uterus, prostate, and thyroid glands. This suggests that Pten ${ }^{F 31 V}$ noncatalytic mutation plays an oncogenic function through a different mechanism than canonical activation of AKT signaling, already shown to predispose to cancer development in vivo (Caserta et al. 2015). Pten knockin mice harboring two cancer-associated mutations, Pten ${ }^{\text {C124S }}$ (protein and lipid phosphatase inactive mutant) and $P t e n^{G 129 E}$ (lipid phosphatase inactive mutant), were also generated. These models were markedly tumor prone and developed tumors that are more aggressive than those developed by Pten heterozygous mutants. Importantly, in the same study, it was also shown that PTEN homodimerizes at the plasma membrane in an active conformation, to exert its lipid phosphatase activity on $\mathrm{PIP}_{3}$, and that catalytically inactive cancer-associated PTEN mutants can heterodimerize with wild-type PTEN and in doing so, inhibit wild-type PTEN catalytic activity in a dominant negative manner. In line with this, heterozygous Pten ${ }^{\mathrm{C1} 24 \mathrm{~S} /+}$ and Pten ${ }^{\text {G129E/+ }}$ tissues also displayed higher levels of PI3K-AKT activation than their wild-type and Pten ${ }^{+-}$counterparts. In summary, in vivo Pten knockin models have revealed that PTEN mutations are not always synonymous with PTEN loss in terms of their aberrant activity, but may also operate through the deregulation of distinct PTEN mechanisms and molecular functions (Papa et al. 2014).

\section{CONCLUDING REMARKS}

Since its discovery as a bona-fide tumor suppressor, numerous in vivo studies have highlighted the variety and importance of PTEN functions, which include inhibition of cellular proliferation, growth and migration, regulation of DNA damage repair, and maintenance of ge- nomic integrity and tumor-suppressive states. As a result of these critical functions, the outcome of PTEN loss proves to be devastating, resulting in the distortion of many pivotal pathways and processes, in turn triggering the dysregulation of embryonic development, cellular homeostasis, and tumorigenesis.

New genetic methods have provided a platform for the study of these effects, and the manipulation of the mouse genome to create multiple mouse colonies designed to decipher specific aspects underlining the biology of cancer initiation and progression. Over time, these GEMMs have yielded a wealth of new data, which have helped us better understand both the cellular and molecular mechanisms involved in tumorigenesis. At first, genetic inactivation of Pten was achieved through whole-body knockout technology with lack of tissue specificity and uncontrolled timing of the genetic inactivation of Pten. However, the utilization of tissue-specific promoters and Cre-mediated recombination (inducible or not) overcame these problems, and enabled the genetic modification of PTEN in a tissue-specific and temporally controlled manner. These approaches offered researchers the opportunity to study in a detailed manner the role of PTEN deregulation in cancer initiation and progression, as well as in a cellular context-specific manner. Recently, comprehensive genetic manipulation of the mouse genome has expanded to take advantage of CRISPR-mediated approaches, which have made possible new combinations of genetic alterations and a far more sophisticated level of genomic editing.

The extensive functional characterization of the roles of PTEN in tumorigenesis in GEMMs has also suggested multiple new targets for drug development, and further facilitated new methods for cancer prevention and therapy. This holds promise for patients coping not only with tumors driven by aberrant PTEN function, but also with disorders caused by germline PTEN mutations.

\section{ACKNOWLEDGMENTS}

The authors thank all the members of the Pandolfi Laboratory for their constructive com- 
ments and Karen Rodzenko and Thomas Garvey for editing of the manuscript. This work was supported by funding from the National Cancer Institute (R35CA197529 to P.P.P.) and a Department of Defense PCRP Postdoctoral Training Award to Y.-R.L.

\section{REFERENCES}

Abate-Shen C, Banach-Petrosky WA, Sun X, Economides KD, Desai N, Gregg JP, Borowsky AD, Cardiff RD, Shen MM. 2003. Nkx3.1; Pten mutant mice develop invasive prostate adenocarcinoma and lymph node metastases. Cancer Res 63: 3886-3890.

Abida W, Cyrta J, Heller G, Prandi D, Armenia J, Coleman I, Cieslik M, Benelli M, Robinson D, Van Allen EM, et al 2019. Genomic correlates of clinical outcome in advanced prostate cancer. Proc Natl Acad Sci 116: 11428-11436. doi:10.1073/pnas.1902651116

Ahmad I, Patel R, Singh LB, Nixon C, Seywright M, Barnetson RJ, Brunton VG, Muller WJ, Edwards J, Sansom OJ, et al. 2011. HER2 overcomes PTEN (loss)-induced senescence to cause aggressive prostate cancer. Proc Natl Acad Sci 108: 16392-16397. doi:10.1073/pnas .1101263108

Alimonti A, Carracedo A, Clohessy JG, Trotman LC, Nardella C, Egia A, Salmena L, Sampieri K, Haveman WJ, Brogi E, et al. 2010a. Subtle variations in Pten dose determine cancer susceptibility. Nat Genet 42: 454-458. doi:10 $.1038 /$ ng.556

Alimonti A, Nardella C, Chen Z, Clohessy JG, Carracedo A, Trotman LC, Cheng K, Varmeh S, Kozma SC, Thomas G, et al. 2010b. A novel type of cellular senescence that can be enhanced in mouse models and human tumor xenografts to suppress prostate tumorigenesis. J Clin Invest 120: 681693. doi:10.1172/JCI40535

Andres-Pons A, Rodriguez-Escudero I, Gil A, Blanco A, Vega A, Molina M, Pulido R, Cid VJ. 2007. In vivo functional analysis of the counterbalance of hyperactive phosphatidylinositol 3-kinase p110 catalytic oncoproteins by the tumor suppressor PTEN. Cancer Res 67: 9731-9739. doi:10.1158/0008-5472.CAN-07-1278

Arch EM, Goodman BK, Van Wesep RA, Liaw D, Clarke K, Parsons R, McKusick VA, Geraghty MT. 1997. Deletion of PTEN in a patient with Bannayan-Riley-Ruvalcaba syndrome suggests allelism with Cowden disease. Am Med Genet 71: 489-493. doi:10.1002/(SICI)1096-8628 (19970905)71:4<489::AID-AJMG24>3.0.CO;2-B

Aytes A, Mitrofanova A, Kinkade CW, Lefebvre C, Lei M, Phelan V, LeKaye HC, Koutcher JA, Cardiff RD, Califano A, et al. 2013. ETV4 promotes metastasis in response to activation of PI3-kinase and Ras signaling in a mouse model of advanced prostate cancer. Proc Natl Acad Sci 110: E3506-E3515. doi:10.1073/pnas.1303558110

Bassi C, Ho J, Srikumar T, Dowling RJ, Gorrini C, Miller SJ, Mak TW, Neel BG, Raught B, Stambolic V. 2013. Nuclear PTEN controls DNA repair and sensitivity to genotoxic stress. Science 341: 395-399. doi:10.1126/sci ence. 1236188
Berger AH, Knudson AG, Pandolfi PP. 2011. A continuum model for tumour suppression. Nature 476: 163-169. doi:10.1038/nature10275

Carver BS, Tran J, Gopalan A, Chen Z, Shaikh S, Carracedo A, Alimonti A, Nardella C, Varmeh S, Scardino PT, et al. 2009. Aberrant ERG expression cooperates with loss of PTEN to promote cancer progression in the prostate. Nat Genet 41: 619-624. doi:10.1038/ng.370

Caserta E, Egriboz O, Wang H, Martin C, Koivisto C, Pecót T, Kladney RD, Shen C, Shim KS, Pham T, et al. 2015. Noncatalytic PTEN missense mutation predisposes to organ-selective cancer development in vivo. Genes Dev 29: 1707-1720. doi:10.1101/gad.262568.115

Chen Z, Trotman LC, Shaffer D, Lin HK, Dotan ZA, Niki M, Koutcher JA, Scher HI, Ludwig T, Gerald W, et al. 2005. Crucial role of p53-dependent cellular senescence in suppression of Pten-deficient tumorigenesis. Nature 436: 725-730. doi:10.1038/nature03918

Chen Y, Chi P, Rockowitz S, Iaquinta PJ, Shamu T, Shukla S, Gao D, Sirota I, Carver BS, Wongvipat J, et al. 2013. ETS factors reprogram the androgen receptor cistrome and prime prostate tumorigenesis in response to PTEN loss. Nat Med 19: 1023-1029. doi:10.1038/nm.3216

Chen M, Zhang J, Sampieri K, Clohessy JG, Mendez L, Gonzalez-Billalabeitia E, Liu XS, Lee YR, Fung J, Katon JM, et al. 2018. An aberrant SREBP-dependent lipogenic program promotes metastatic prostate cancer. Nat Genet 50: 206-218. doi:10.1038/s41588-017-0027-2

Chung JH, Ginn-Pease ME, Eng C. 2005. Phosphatase and tensin homologue deleted on chromosome 10 (PTEN) has nuclear localization signal-like sequences for nuclear import mediated by major vault protein. Cancer Res 65: 4108-4116. doi:10.1158/0008-5472.CAN-05-0124

Civenni G, Carbone GM, Catapano CV. 2018. Overview of genetically engineered mouse models of prostate cancer and their applications in drug discovery. Curr Protoc Pharmacol 81: e39. doi:10.1002/cpph.39

Di Cristofano A, Pandolfi PP. 2000. The multiple roles of PTEN in tumor suppression. Cell 100: 387-390. doi:10 .1016/S0092-8674(00)80674-1

Di Cristofano A, Pesce B, Cordon-Cardo C, Pandolfi PP. 1998. Pten is essential for embryonic development and tumour suppression. Nat Genet 19: 348-355. doi:10 $.1038 / 1235$

Di Cristofano A, Kotsi P, Peng YF, Cordon-Cardo C, Elkon KB, Pandolfi PP. 1999. Impaired Fas response and autoimmunity in Pten ${ }^{+-}$mice. Science 285: 2122-2125. doi:10.1126/science.285.5436.2122

Di Cristofano A, De Acetis M, Koff A, Cordon-Cardo C, Pandolfi PP. 2001. Pten and p27KIP1 cooperate in prostate cancer tumor suppression in the mouse. Nat Genet 27: 222-224. doi:10.1038/84879

Ding Z, Wu CJ, Chu GC, Xiao Y, Ho D, Zhang J, Perry SR, Labrot ES, Wu X, Lis R, et al. 2011. SMAD4-dependent barrier constrains prostate cancer growth and metastatic progression. Nature 470: 269-273. doi:10.1038/nature 09677

Ding Z, Wu CJ, Jaskelioff M, Ivanova E, Kost-Alimova M, Protopopov A, Chu GC, Wang G, Lu X, Labrot ES, et al. 2012. Telomerase reactivation following telomere dysfunction yields murine prostate tumors with bone metastases. Cell 148: 896-907. doi:10.1016/j.cell.2012.01.039 
Garcia-Cao I, Song MS, Hobbs RM, Laurent G, Giorgi C, de Boer VC, Anastasiou D, Ito K, Sasaki AT, Rameh L, et al. 2012. Systemic elevation of PTEN induces a tumor-suppressive metabolic state. Cell 149: 49-62. doi:10.1016/j cell.2012.02.030

Horie Y, Suzuki A, Kataoka E, Sasaki T, Hamada K, Sasaki J, Mizuno K, Hasegawa G, Kishimoto H, Iizuka M, et al. 2004. Hepatocyte-specific Pten deficiency results in steatohepatitis and hepatocellular carcinomas. J Clin Invest 113: 1774-1783. doi:10.1172/JCI20513

Hubbard GK, Mutton LN, Khalili M, McMullin RP, Hicks JL, Bianchi-Frias D, Horn LA, Kulac I, Moubarek MS Nelson PS, et al. 2016. Combined MYC activation and Pten loss are sufficient to create genomic instability and lethal metastatic prostate cancer. Cancer Res 76: 283-292. doi:10.1158/0008-5472.CAN-14-3280

Inoue K, Fry EA, Taneja P. 2013. Recent progress in mouse models for tumor suppressor genes and its implications in human cancer. Clin Med Insights Oncol 7: 103-122. doi:10.4137/CMO.S10358

Kim MJ, Cardiff RD, Desai N, Banach-Petrosky WA, Parsons R, Shen MM, Abate-Shen C. 2002. Cooperativity of Nkx3.1 and Pten loss of function in a mouse model of prostate carcinogenesis. Proc Natl Acad Sci 99: 28842889. doi:10.1073/pnas.042688999

Kishimoto H, Hamada K, Saunders M, Backman S, Sasaki T, Nakano T, Mak TW, Suzuki A. 2003. Physiological functions of Pten in mouse tissues. Cell Struct Funct 28: 11-21. doi:10.1247/csf.28.11

Kuchay S, Giorgi C, Simoneschi D, Pagan J, Missiroli S, Saraf A, Florens L, Washburn MP, Collazo-Lorduy A, CastilloMartin M, et al. 2017. PTEN counteracts FBXL2 to promote IP3R3- and $\mathrm{Ca}^{2+}$-mediated apoptosis limiting tumour growth. Nature 546: 554-558. doi:10.1038/na ture22965

Kwon OJ, Zhang L, Wang J, Su Q, Feng Q, Zhang XH, Mani SA, Paulter R, Creighton CJ, Ittmann MM, et al. 2016. Notch promotes tumor metastasis in a prostate-specific Pten-null mouse model. J Clin Invest 126: 2626-2641. doi:10.1172/JCI84637

Lee YR, Chen M, Pandolfi PP. 2018. The functions and regulation of the PTEN tumour suppressor: new modes and prospects. Nat Rev Mol Cell Biol 19: 547-562. doi:10 .1038/s41580-018-0015-0

Lee YR, Chen M, Lee JD, Zhang J, Lin SY, Fu TM, Chen H, Ishikawa T, Chiang SY, Katon J, et al. 2019. Reactivation of PTEN tumor suppressor for cancer treatment through inhibition of a MYC-WWP1 inhibitory pathway. Science 364: eaau0159. doi:10.1126/science.aau0159

Li J, Yen C, Liaw D, Podsypanina K, Bose S, Wang SI, Puc J, Miliaresis C, Rodgers L, McCombie R, et al. 1997. PTEN, a putative protein tyrosine phosphatase gene mutated in human brain, breast, and prostate cancer. Science 275: 1943-1947. doi:10.1126/science.275.5308.1943

Li G, Robinson GW, Lesche R, Martinez-Diaz H, Jiang Z, Rozengurt N, Wagner KU, Wu DC, Lane TF, Liu X, et al. 2002. Conditional loss of PTEN leads to precocious development and neoplasia in the mammary gland. Development 129: 4159-4170.

Liaw D, Marsh DJ, Li J, Dahia PL, Wang SI, Zheng Z, Bose S, Call KM, Tsou HC, Peacocke M, et al. 1997. Germline mutations of the PTEN gene in Cowden disease, an in- herited breast and thyroid cancer syndrome. Nat Genet 16: 64-67. doi:10.1038/ng0597-64

Ma L, Teruya-Feldstein J, Behrendt N, Chen Z, Noda T, Hino O, Cordon-Cardo C, Pandolfi PP. 2005. Genetic analysis of Pten and Tsc2 functional interactions in the mouse reveals asymmetrical haploinsufficiency in tumor suppression. Genes Dev 19: 1779-1786. doi:10.1101/gad .1314405

Mester JL, Tilot AK, Rybicki LA, Frazier TW II, Eng C. 2011. Analysis of prevalence and degree of macrocephaly in patients with germline PTEN mutations and of brain weight in Pten knock-in murine model. Eur J Hum Genet 19: 763-768. doi:10.1038/ejhg.2011.20

Mulholland DJ, Kobayashi N, Ruscetti M, Zhi A, Tran LM, Huang J, Gleave M, Wu H. 2012. Pten loss and RAS/ MAPK activation cooperate to promote EMT and metastasis initiated from prostate cancer stem/progenitor cells. Cancer Res 72: 1878-1889. doi:10.1158/0008-5472.CAN11-3132

Nacerddine K, Beaudry JB, Ginjala V, Westerman B, Mattiroli F, Song JY, van der Poel H, Ponz OB, Pritchard C, Cornelissen-Steijger P, et al. 2012. Akt-mediated phosphorylation of Bmil modulates its oncogenic potential, E3 ligase activity, and DNA damage repair activity in mouse prostate cancer. J Clin Invest 122: 1920-1932. doi:10.1172/JCI57477

Nguyen AH, Tremblay M, Haigh K, Koumakpayi IH, Paquet M, Pandolfi PP, Mes-Masson AM, Saad F, Haigh JJ, Bouchard M. 2013. Gata3 antagonizes cancer progression in Pten-deficient prostates. Hum Mol Genet 22: 2400-2410. doi:10.1093/hmg/ddt088

Papa A, Wan L, Bonora M, Salmena L, Song MS, Hobbs RM, Lunardi A, Webster K, Ng C, Newton RH, et al. 2014. Cancer-associated PTEN mutants act in a dominant-negative manner to suppress PTEN protein function. Cell 157: 595-610. doi:10.1016/j.cell.2014.03.027

Podsypanina K, Ellenson LH, Nemes A, Gu J, Tamura M, Yamada KM, Cordon-Cardo C, Catoretti G, Fisher PE, Parsons R. 1999. Mutation of Pten/Mmacl in mice causes neoplasia in multiple organ systems. Proc Natl Acad Sci 96: 1563-1568. doi:10.1073/pnas.96.4.1563

Renner O, Carnero A. 2009. Mouse models to decipher the PI3K signaling network in human cancer. Curr Mol Med 9: 612-625. doi:10.2174/156652409788488766

Renner O, Blanco-Aparicio C, Carnero A. 2008. Genetic modelling of the PTEN/AKT pathway in cancer research. Clin Transl Oncol 10: 618-627. doi:10.1007/s12094-0080262-1

Robinson D, Van Allen EM, Wu YM, Schultz N, Lonigro RJ, Mosquera JM, Montgomery B, Taplin ME, Pritchard CC, Attard G, et al. 2015. Integrative clinical genomics of advanced prostate cancer. Cell 161: 1215-1228. doi:10 .1016/j.cell.2015.05.001

Salmena L, Carracedo A, Pandolfi PP. 2008. Tenets of PTEN tumor suppression. Cell 133: 403-414. doi:10.1016/j.cell .2008 .04 .013

Song MS, Carracedo A, Salmena L, Song SJ, Egia A, Malumbres M, Pandolfi PP. 2011. Nuclear PTEN regulates the APC-CDH1 tumor-suppressive complex in a phosphatase-independent manner. Cell 144: 187-199. doi:10 $.1016 /$ j.cell.2010.12.020 
Y.-R. Lee and P.P. Pandolfi

Song MS, Salmena L, Pandolfi PP. 2012. The functions and regulation of the PTEN tumour suppressor. Nat Rev Mol Cell Biol 13: 283-296. doi:10.1038/nrm3330

Suzuki A, de la Pompa JL, Stambolic V, Elia AJ, Sasaki T, del Barco Barrantes I, Ho A, Wakeham A, Itie A, Khoo W, et al. 1998. High cancer susceptibility and embryonic lethality associated with mutation of the PTEN tumor suppressor gene in mice. Curr Biol 8: 1169-1178. doi:10.1016/ S0960-9822(07)00488-5

Suzuki A, Yamaguchi MT, Ohteki T, Sasaki T, Kaisho T, Kimura Y, Yoshida R, Wakeham A, Higuchi T, Fukumoto M, et al. 2001. T cell-specific loss of Pten leads to defects in central and peripheral tolerance. Immunity 14: 523-534 doi:10.1016/S1074-7613(01)00134-0

Teng DH, Hu R, Lin H, Davis T, Iliev D, Frye C, Swedlund B, Hansen KL, Vinson VL, Gumpper KL, et al. 1997. MMAC1/PTEN mutations in primary tumor specimens and tumor cell lines. Cancer Res 57: 5221-5225.

Thomsen MK, Ambroisine L, Wynn S, Cheah KS, Foster CS, Fisher G, Berney DM, Moller H, Reuter VE, Scardino P, et al. 2010. SOX9 elevation in the prostate promotes proliferation and cooperates with PTEN loss to drive tumor formation. Cancer Res 70: 979-987. doi:10.1158/00085472.CAN-09-2370

Tilot AK, Gaugler MK, Yu Q, Romigh T, Yu W, Miller RH, Frazier TW II, Eng C. 2014. Germline disruption of Pten localization causes enhanced sex-dependent social motivation and increased glial production. Hum Mol Genet 23: 3212-3227. doi:10.1093/hmg/ddu031

Trotman LC, Niki M, Dotan ZA, Koutcher JA, Di Cristofano A, Xiao A, Khoo AS, Roy-Burman P, Greenberg NM, Van Dyke T, et al. 2003. Pten dose dictates cancer progression in the prostate. PLoS Biol 1: E59. doi:10.1371/journal.pbio 0000059

Trotman LC, Wang X, Alimonti A, Chen Z, Teruya-Feldstein J, Yang H, Pavletich NP, Carver BS, Cordon-Cardo C, Erdjument-Bromage $\mathrm{H}$, et al. 2007. Ubiquitination regulates PTEN nuclear import and tumor suppression. Cell 128: 141-156. doi:10.1016/j.cell.2006.11.040

Vogelstein B, Lane D, Levine AJ. 2000. Surfing the p53 network. Nature 408: 307-310. doi:10.1038/35042675

Wang J, Kobayashi T, Floc'h N, Kinkade CW, Aytes A, Dankort D, Lefebvre C, Mitrofanova A, Cardiff RD, McMa- hon M, et al. 2012. B-Raf activation cooperates with PTEN loss to drive c-Myc expression in advanced prostate cancer. Cancer Res 72: 4765-4776. doi:10.1158/0008 5472.CAN-12-0820

Wang G, Lunardi A, Zhang J, Chen Z, Ala U, Webster KA, Tay Y, Gonzalez-Billalabeitia E, Egia A, Shaffer DR, et al. 2013. Zbtb7a suppresses prostate cancer through repression of a Sox9-dependent pathway for cellular senescence bypass and tumor invasion. Nat Genet 45: 739-746. doi:10.1038/ng.2654

Wang D, Mou H, Li S, Li Y, Hough S, Tran K, Li J, Yin H, Anderson DG, Sontheimer EJ, et al. 2015. AdenovirusMediated somatic genome editing of Pten by CRISPR/ Cas9 in mouse liver in spite of Cas9-specific immune responses. Hum Gene Ther 26: 432-442. doi:10.1089/ hum.2015.087

Xue W, Chen S, Yin H, Tammela T, Papagiannakopoulos T, Joshi NS, Cai W, Yang G, Bronson R, Crowley DG, et al. 2014. CRISPR-mediated direct mutation of cancer genes in the mouse liver. Nature 514: 380-384. doi:10.1038/ nature 13589

Yan H, Dobbie Z, Gruber SB, Markowitz S, Romans K, Giardiello FM, Kinzler KW, Vogelstein B. 2002. Small changes in expression affect predisposition to tumorigenesis. Nat Genet 30: 25-26. doi:10.1038/ng799

Yehia L, Ngeow J, Eng C. 2019. PTEN-opathies: from biological insights to evidence-based precision medicine. $J$ Clin Invest 129: 452-464. doi:10.1172/JCI121277

Zhao D, Lu X, Wang G, Lan Z, Liao W, Li J, Liang X, Chen JR, Shah S, Shang X, et al. 2017. Synthetic essentiality of chromatin remodelling factor CHD1 in PTEN-deficient cancer. Nature 542: 484-488. doi:10.1038/nature21357

Zhong C, Saribekyan G, Liao CP, Cohen MB, Roy-Burman P. 2006. Cooperation between FGF8b overexpression and PTEN deficiency in prostate tumorigenesis. Cancer Res 66: 2188-2194. doi:10.1158/0008-5472.CAN-05-3440

Zhou X, Hampel H, Thiele H, Gorlin RJ, Hennekam RC, Parisi M, Winter RM, Eng C. 2001. Association of germline mutation in the PTEN tumour suppressor gene and proteus and proteus-like syndromes. Lancet 358: 210 211. doi:10.1016/S0140-6736(01)05412-5 


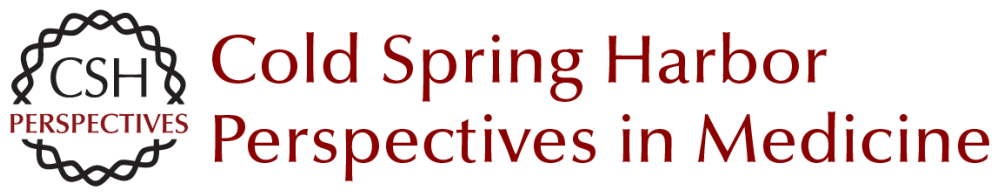

\section{PTEN Mouse Models of Cancer Initiation and Progression}

Yu-Ru Lee and Pier Paolo Pandolfi

Cold Spring Harb Perspect Med 2020; doi: 10.1101/cshperspect.a037283 originally published online September 30, 2019

\section{Subject Collection The PTEN Family}

PTEN in Regulating Hematopoiesis and Leukemogenesis

Yilin Wu, Haichuan Zhu and Hong Wu

Connecting Genotype with Behavioral Phenotype

in Mouse Models of Autism Associated with

PTEN Mutations

Amy E. Clipperton-Allen and Damon T. Page

Metabolic Role of PTEN in Insulin Signaling and

Resistance

Yu Zhe Li, Antonio Di Cristofano and Minna Woo

Posttranslational Regulation and Conformational

Plasticity of PTEN

Larissa Kotelevets, Barbara Trifault, Eric Chastre, et al.

Toward Systems Pathology for PTEN Diagnostics Nahal Haddadi, Glena Travis, Najah T. Nassif, et al.

PTEN in Hereditary and Sporadic Cancer Joanne Ngeow and Charis Eng

PTEN Mouse Models of Cancer Initiation and Progression Yu-Ru Lee and Pier Paolo Pandolfi

Dual-Specific Protein and Lipid Phosphatase

PTEN and Its Biological Functions

Taojian Tu, Jingyu Chen, Lulu Chen, et al.
PTEN: Bridging Endocytosis and Signaling Matthew F. Lee and Lloyd C. Trotman

PTEN as a Guardian of the Genome: Pathways and Targets

Xinyi Fan, Jeffrey Kraynak, Jonathan P.S. Knisely, et al.

Discovery of the PTEN Tumor Suppressor and Its

Connection to the PI3K and AKT Oncogenes Ramon Parsons

The Complex Landscape of PTEN mRNA

Regulation

Erin Sellars, Martino Gabra and Leonardo Salmena

PTEN Nuclear Functions Jason Ho, Edward S. Cruise, Ryan J.O. Dowling, et al.

Structural Mechanisms of PTEN Regulation Glenn R. Masson and Roger L. Williams

PTEN in Chromatin Remodeling Jingyi Yang and Yuxin Yin

The Role of PTEN in Innate and Adaptive Immunity

Henry Taylor, Arian D. J. Laurence and Holm H. Uhlig

For additional articles in this collection, see http://perspectivesinmedicine.cshlp.org/cgi/collection/ 